\title{
A rapid method for determination of polar compounds in used frying fats and oils
}

\author{
By S. Marmesat, J. Velasco, G. Márquez-Ruiz and M.C. Dobarganes* \\ Instituto de la Grasa (CSIC). Avda. Padre García Tejero, 4. \\ 41012 Sevilla (Spain) \\ *To whom correspondence should be addressed: \\ Telephone: +34954611550 \\ Fax: $\quad+34954616790$ \\ E-mail: cobobar@cica.es
}

\section{RESUMEN}

\section{Método rápido para la determinación de compuestos} polares en aceites y grasas de fritura.

La determinación de compuestos polares mediante cromatografía de adsorción es el método más aceptado en e análisis de aceites y grasas de fritura debido a su elevada exactitud y precisión. Sin embargo, la determinación es costosa, debido al elevado consumo de sílice y disolventes, y son necesarias varias horas para la obtención del resultado. En este estudio se propone una determinación alternativa rápida. Partiendo de miligramos de muestra disueltos en una solución de hexano con oleato de metilo como patrón interno, la fracción no polar, que contiene los triglicéridos no alterados y el patrón interno, es aislada mediante extracción en fase sólida. Posteriormente, la fracción no polar se analiza cuantitativamente en 15 min mediante cromatografía líquida de exclusión y la cantidad de fracción polar se determina por diferencia de peso. Se han calculado los factores de respuesta de triglicéridos y ésteres metílicos. El método se ha aplicado a seis muestras de aceites de girasol de distinto grado de insaturación evaluadas por triplicado y los resultados se han comparado con los obtenidos mediante la determinación gravimétrica basada en cromatografía en columna clásica de sílice. No se han encontrado diferencias significativas entre los dos grupos de resultados. Por otra parte, la repetibilidad fue excelente ya que los coeficientes de variación oscilaron entre 1.5 y $13 \%$ dependiendo del contenido en compuestos polares de los aceites.

PALABRAS-CLAVE: Aceites y grasas de fritura - Compuestos polares - Cromatografía de exclusión - Extracción en fase sólida - Factores de respuesta.

\section{SUMMARY}

A rapid method for determination of polar compounds in used frying fats and oils.

The determination of polar compounds by adsorption chromatography is the most accepted method for the analysis of used frying fats due to its high precision and accuracy. However, this method is expensive and time consuming. In this study, a rapid analytical method to determine polar compounds is proposed. Starting from milligrams of sample dissolved in a solution of hexane containing methyl oleate as internal standard, the nonpolar fraction, which comprises the non-altered triglycerides (TG) and the internal standard, is obtained by solid phase extraction. Then, the non polar fraction is quantitatively analyzed in $15 \mathrm{~min}$ by high-performance size-exclusion chromatography (HPSEC) and the polar fraction is determined by difference of weight. Response factors for pure TG and FAME were calculated. Six samples of sunflower oils of different degrees of unsaturation were analyzed in triplicate and the results were compared with those obtained by the gravimetric method based on silica classical column chromatography. Results showed no significant differences between the two methods. In addition, the repeatability of the proposed method was excellent, as the coefficient of variation ranged from 1.5 to $13 \%$ depending on the contents of polar compounds.

KEY-WORDS: Polar compounds - Response factors Size exclusion chromatography - Solid phase extraction - Used frying oils.

\section{INTRODUCTION}

The determinations of polar compounds and polymers are the two most recommended analytical techniques for the quality control of used frying fats and oils (DGF, 2000; Marmesat et al., 2007). On one hand, the determination of polar compounds gives information on the total amount of new compounds formed. It is a precise and accurate gravimetric method based on adsorption chromatography on silica classical column although it is expensive and time consuming (IUPAC, 1992 a). A reduction in solvents and silica has been proposed but it continues to be a time consuming technique (Dieffenbacher and Martin, 1987; Dobarganes et al., 2000). Limits of around $25 \%$ of polar compounds to discard used frying fats for human consumption have been proposed in different countries (Firestone, 1996). Therefore, the standard method is the most applied and accepted technique in the analysis of used frying fats.

On the other hand, polymers are the most characteristic group of compounds formed at high temperatures from the early stages of heating. The standard determination by high-performance sizeexclusion chromatography (HPSEC) with refraction index $(\mathrm{RI})$ detection allows for their quantification in 10-15 minutes (IUPAC, 1992 b). Given the simplicity of the HPSEC technique, the determination of polymers has been recently proposed as a good method to control the quality of used frying fats. A 
maximum content of $12 \%$ has been suggested for discarding used frying fats (DGF, 2000).

In this study, we propose a rapid method for the determination of polar compounds taking advantage of the HPSEC technique used for polymer determination. Starting from milligrams of sample, the non-polar fraction is obtained by solid phase extraction and determined by HPSEC with a fatty acid methyl ester as internal standard. Toward this end, response factors of pure fatty acid methyl esters (FAME), pure triglycerides (TG), as well as FAME and TG obtained from oils of different degrees of unsaturation were calculated to increase the accuracy of the determination.

\section{EXPERIMENTAL}

\subsection{Samples and treatments}

Methyl stearate, methyl oleate, methyl linoleate, tristearin, triolein and trilinolein were supplied by Nu-Chek-Prep. (Elysian, MN, USA). Ten samples with concentrations between 3 and $50 \mathrm{mg} / \mathrm{mL}$ were analyzed to determine the response of the pure compounds by refractive index (RI) detection.

Conventional high linoleic sunflower oil (HLSO) was acquired from a local market. Genetically modified high oleic sunflower oil (HOSO) and high palmitic sunflower oils (HPSO) obtained from mutant sunflower seeds (Guinda et al., 2003) were extracted and refined in the pilot plant of the Instituto de la Grasa. Purified TG and FAME were obtained from the oils by silica column under the conditions established for the elution of the nonpolar fraction, i.e, petroleum ether: ethyl ether 87:13 (v/v) for TG (IUPAC, 1992 a) and petroleum ether: ethyl ether 95:5 (v/v) for FAME (Dobarganes et al., 1984). Response factors were also calculated starting from 10 samples of different concentrations in each case. Fatty acid compositions in terms of saturated, monounsaturated and diunsaturated FAME are given in Table 1.

Two samples of HOPO, HOSO and HLSO from laboratory frying experiments that covered a wide range of polar compounds were analyzed in triplicate.

\subsection{Analytical determinations}

Separation of the non-polar fraction by adsorption chromatography

Used frying oils were fractionated using silica cartridges for solid-phase extraction (Sep-pak columns supplied by Waters Associates, Milford, MA, USA). Briefly, a sample of $30-50 \mathrm{mg}$ of oil accurately weighed was dissolved in $2 \mathrm{~mL}$ of a solution of hexane containing the internal standard ( $8 \mathrm{mg} / \mathrm{mL}$ of methyl oleate in hexane) and placed on the silica cartridge. The solvent was passed through while the sample was retained on the column. Then, the non-polar fraction was eluted
Table 1

Fatty acid composition of sunflower oils

\begin{tabular}{cccc}
\hline Oil & $\begin{array}{c}\text { Saturated } \\
\text { fame }\end{array}$ & $\begin{array}{c}\text { Monounsaturated } \\
\text { fame }\end{array}$ & $\begin{array}{c}\text { Diunsaturated } \\
\text { fame }\end{array}$ \\
\hline HPSO & 29.6 & 67.7 & 2.7 \\
HOSO & 8.8 & 84.7 & 6.5 \\
HLSO & 9.9 & 32.3 & 57.8 \\
\hline
\end{tabular}

HPSO, high palmitic sunflower oil; HOSO, high oleic sunflower oil; HLSO, high linoleic sunflower oil

with $15 \mathrm{~mL}$ of $90: 10$ pentroleum ether:diethyl ether $(\mathrm{v} / \mathrm{v})$. After solvent evaporation, the sample was again dissolved in $2 \mathrm{~mL}$ of tetrahydrofuran for further analysis by HPSEC.

A second fraction containing the polar compounds was obtained with $15 \mathrm{~mL}$ of diethyl ether to check the efficiency of the separation by TLC. Thus, the separation of the fractions was routinely monitored by TLC, using small plates of Silica Gel $60(5 \times 10$ $\mathrm{cm}$ plates, $0.25 \mathrm{~mm}$ thickness). The plates were deliberately overloaded, eluted with light petroleumdiethyl ether-acetic acid (80:20:1, v/v/v) and visualized with iodine vapor. A neat separation between the two fractions was normally found.

\section{High-performance size-exclusion chromatography}

The non-polar fraction of used frying fats and oils, obtained as outlined above, was analyzed by HPSEC using a chromatograph equipped with a Rheodyne 7725i injector with a $10-\mu \mathrm{L}$ sample loop, a Waters 510 pump (Waters Associates, Milford, MA, USA) and an HP 1037 A refractive index detector (Agilent Technologies, Palo Alto, CA). The separation was performed on two 100 and $500 \AA$ Ultrastyragel columns $(25 \mathrm{~cm} \times 0.77 \mathrm{~cm}$ I.D. $)$ packed with porous, highly cross-linked styrenedivinyl-benzene copolymers (film thickness $10 \mu \mathrm{m}$ ) (Hewlett Packard, Avondale, PA, USA) connected in series, with tetrahydrofuran $(1 \mathrm{~mL} / \mathrm{min})$ as the mobile phase (Dobarganes et al., 1988).

\section{Determination of the polar compounds}

For comparative purposes, the IUPAC standard method was applied to the used frying oils to determine the polar compounds (IUPAC, 1992a).

\section{Fatty acid composition}

Analysis of fatty acids was performed in the oils by $\mathrm{GC}$ after derivatization to FAME with $2 \mathrm{~N} \mathrm{KOH}$ in methanol (AENOR, 1991). FAME were analyzed by GLC using an HP 6890 chromatograph equipped with an HP Innowax capillary column: $30 \mathrm{~m} \times 0.25$ $\mathrm{mm}$ i.d., film thickness $0.25 \mu \mathrm{m}$ (Hewlett Packard, Avondale, PA, USA). The analyses were run at $200^{\circ} \mathrm{C}$. Samples were introduced into the column via a split injector (split ratio $1: 40$ ) at $250{ }^{\circ} \mathrm{C}$ and the flow rate of hydrogen, used as carrier gas, was 
$1 \mathrm{~mL} / \mathrm{min}$. The temperature of both split injector and flame ionization detector was $250^{\circ} \mathrm{C}$.

\subsection{Statistical analysis}

Statistical analysis was applied by Microsoft Excel 2000 (Microsoft Co., WA, USA).

\section{RESULTS AND DISCUSSION}

Figures 1 and 2 show the linear relationships between sample concentration and $\mathrm{RI}$ response (peak area) obtained by HPSEC analysis for the pure FAME and pure TG, respectively. The linear regression equations have been included in the figures. In all the cases the intercepts were not significantly different from zero $(P<0.05)$. For each type of lipids, significant differences $(P<0.05)$ were found between the slopes as a function of the degree of unsaturation. Thus, the higher the degree of unsaturation of the standard, the higher the RI response was. Furthermore, the slopes for TG were higher than those for FAME of the same degree of unsaturation. Therefore, the TG showed higher responses than their parent FAME.

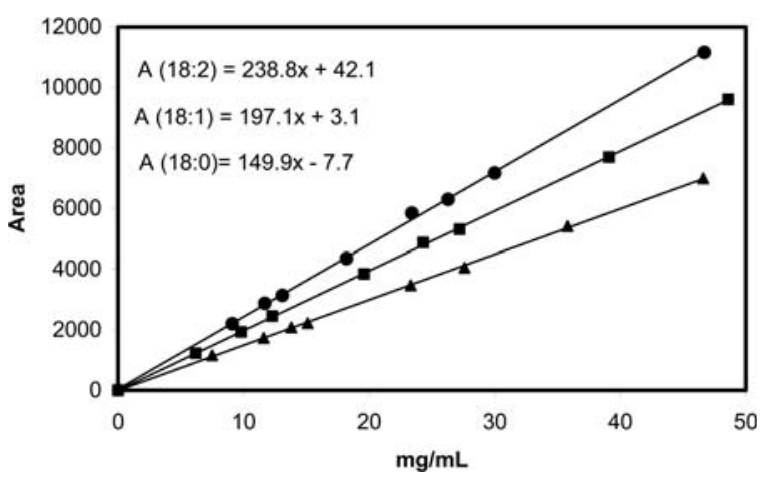

Figure 1

Linear regression between concentration of pure fatty acid methyl ester and its response in high-performance size-exclusion chromatography with refractive index detection

( $\Delta$ methyl stearate; methyl oleate; methyl linoleate).

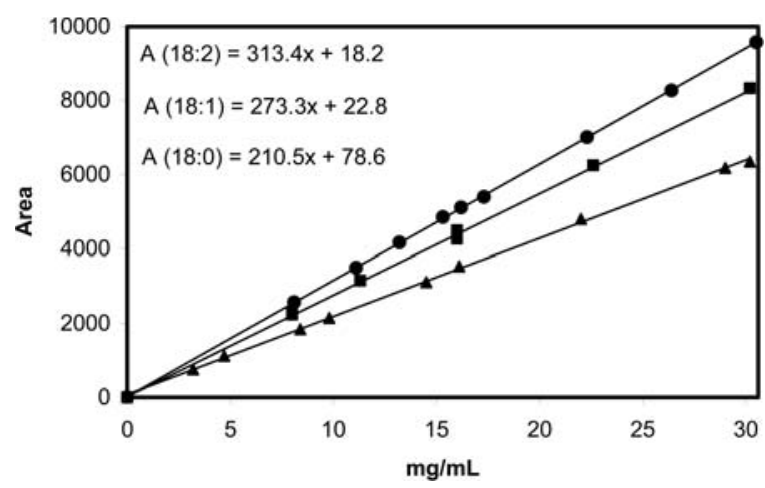

Figure 2

Linear regression between concentration

of pure triglyceride and its response in high-performance size-exclusion chromatography with refractive index detection

( $\Delta$ tristearin; $\mathbf{\square}$ triolein; trilinolein).
Concerning the influence of the degree of unsaturation as well as statistical significance, similar results were found for purified FAME and TG obtained from the sunflower oils (Figures 3 and 4). The slopes of the regression lines showed intermediate values between the minimum and maximum values observed in the pure lipids. Thus, the slopes for sunflower oil FAME were between those found for methyl stearate and methyl linoleate, and the slopes for sunflower oil TG were between those for tristearin and triolein, which was expected considering their intermediate degree of unsaturation.

Tables 2 and 3 list the linear regression parameters and response factors obtained for FAME and TG, respectively. The response factors were expressed as relative to methyl stearate and tristearin, respectively. In addition, the response factors for oil FAME were also calculated taking into account the fatty acid composition of the three oils (Table 1). As shown in Table 2, the calculated

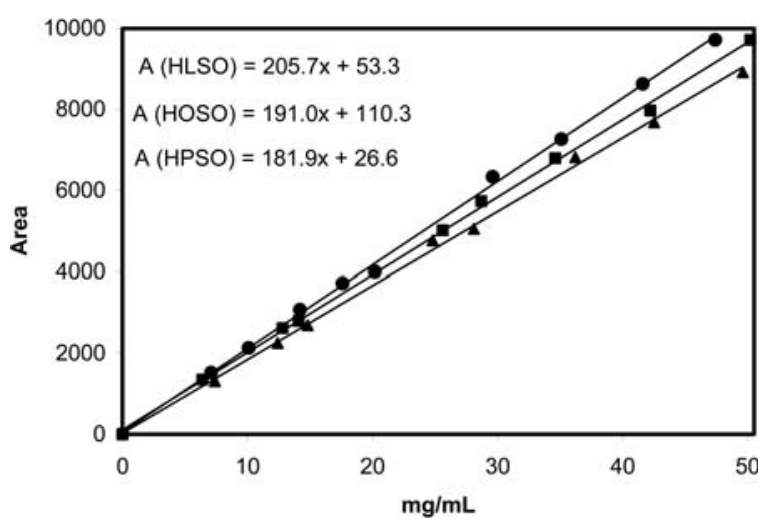

Figure 3

Linear regression between concentration of fatty acid methyl esters from sunflower oils and their response in high performance-size exclusion-chromatography with refractive index detection ( $\boldsymbol{\Delta}$ high palmitic sunflower oil; high oleic sunflower oil; 1 high linoleic sunflower oil).

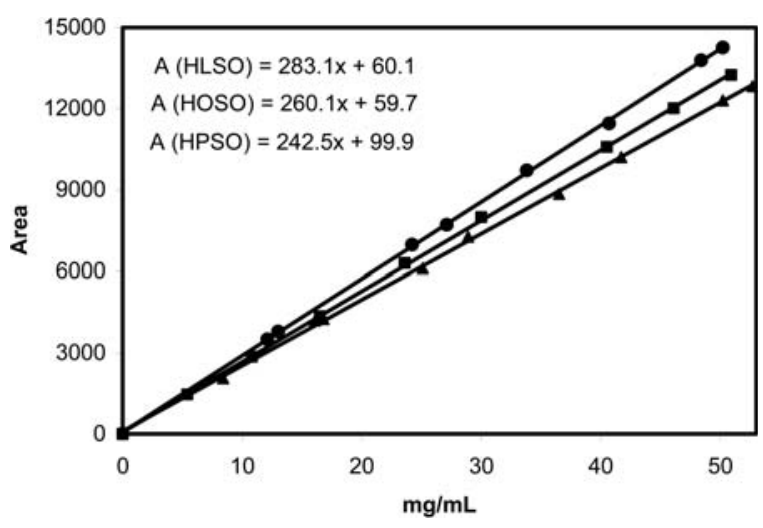

Figure 4

Linear regression between concentration of triglycerides from sunflower oils and their response in high-performance size-exclusion chromatography with refractive index detection

( $\boldsymbol{\Delta}$ high palmitic sunflower oil; $\boldsymbol{\square}$ high oleic sunflower oil; high linoleic sunflower oil). 
Table 2

Linear regression parameters and relative response factors for fatty acid methyl esters.

\begin{tabular}{lcccc}
\hline FAME & Slope & $\begin{array}{c}\text { Correlation } \\
\text { coefficient }\end{array}$ & $\begin{array}{c}\text { Response } \\
\text { factor }\end{array}$ & $\begin{array}{c}\text { Calculated } \\
\text { Response } \\
\text { factor * }\end{array}$ \\
\hline C18:0 & 150 & 0.9998 & 1 & \\
C18:1 & 197 & 0.9999 & 1.31 & \\
C18:2 & 239 & 0.9997 & 1.59 & \\
HPSO & 182 & 0.9991 & 1.21 & 1.22 \\
HOSO & 191 & 0.9995 & 1.27 & 1.28 \\
HLSO & 205 & 0.9994 & 1.37 & 1.38 \\
\hline
\end{tabular}

For abbreviations see Table $1 ;{ }^{*}$ calculated from FAME in Table 1

Table 3

Linear regression parameters and relative response factors for triglycerides.

\begin{tabular}{cccc}
\hline Triglycerides & Slope & $\begin{array}{c}\text { Correlation } \\
\text { coefficient }\end{array}$ & $\begin{array}{c}\text { Response } \\
\text { factor }\end{array}$ \\
\hline Triestearin & 210 & 0.9996 & 1 \\
Triolein & 273 & 0.9904 & 1.30 \\
Trilinolein & 313 & 0.9999 & 1.49 \\
HPSO & 242 & 0.9997 & 1.15 \\
HOSO & 260 & 0.9998 & 1.24 \\
HLSO & 283 & 0.9998 & 1.33 \\
\hline
\end{tabular}

For abbreviations see Table 1 .

response factors were practically identical to those obtained experimentally. From the results in Tables 2 and 3 , it was deduced that the application of response factors would significantly improve the accuracy of the non-polar triglycerides quantification. Furthermore, any of the FAME samples, either pure compounds or purified from oils, can be used as internal standard in the determination of polar compounds.

Quantitation of the polar compounds in the samples of HOPO, HOSO and HLSO from laboratory frying experiments was carried out using methyl oleate as internal standard. The selection of the internal standard was based on its solubility and low susceptibility to oxidation, although any methyl ester can be used as internal standard due to the good separation obtained between the peaks. Typical chromatograms for the non-polar fractions obtained by the standard method, i.e. gravimetric determination and by the method proposed in this study using methyl oleate as internal standard are shown in Figure 5. As can be observed, the nonpolar TG elute as a single peak and a perfect separation from the internal standard is obtained due to their differences in MW. Once the non-polar fraction is quantified, the polar fraction is determined by difference of weight as in the standard determination (IUPAC, 1992 a). Table 4 shows the response factors, as well as the correction factors, expressed as relative to methyl oleate, found for each oil. The result obtained by taking the overall data for the three oils in the linear

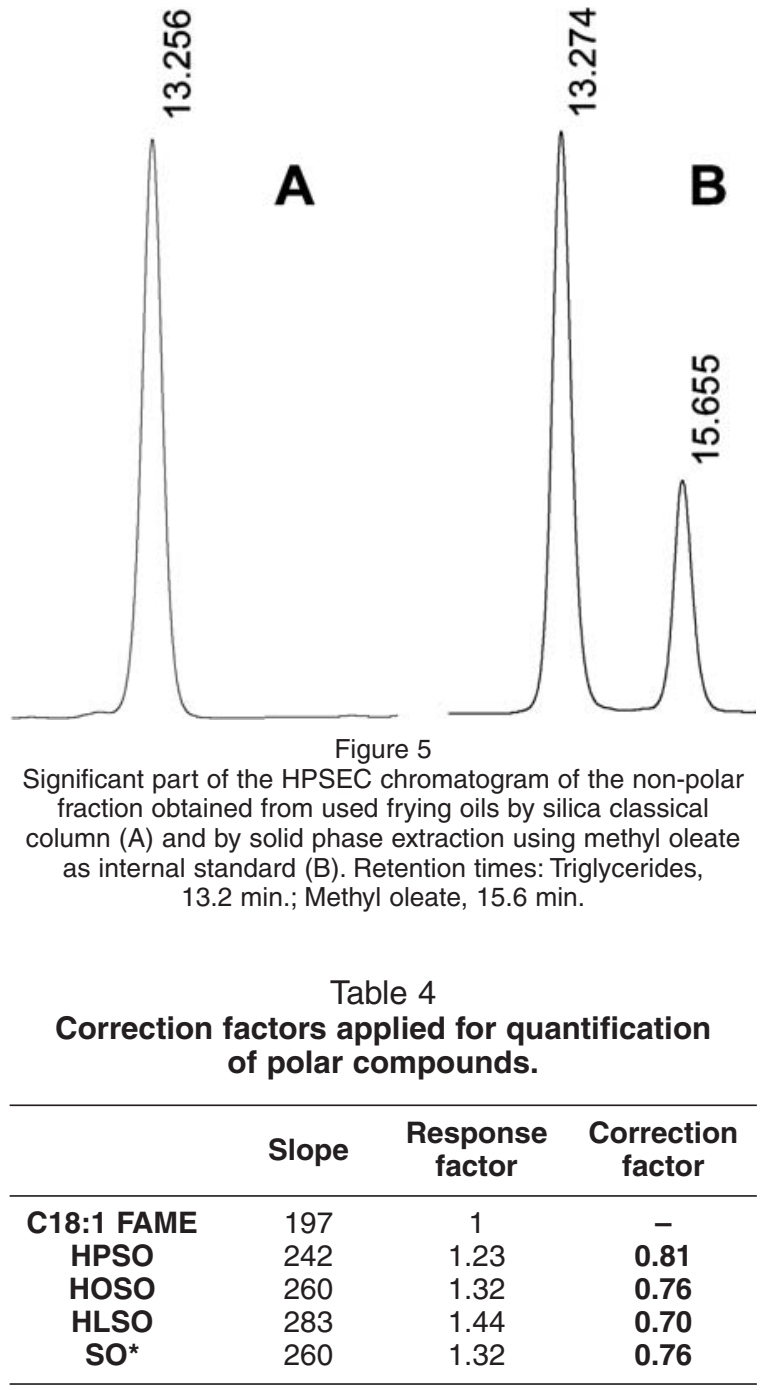

For abbreviations see Table $1 ;{ }^{*}$ From linear regression considering the data for the three sunflower oils $(R=0.9920)$.

regression analysis has also been included $(R=$ $0.9920)$. Given that, in practice, the composition of the oils selected covers the degree of unsaturation of the oils and fats used in frying, the mean correction factor found $(0.76)$ was considered for the quantification of the polar compounds.

Quantitative data are listed in Table 5. Results obtained by applying the corresponding correction factors for each oil as well as the mean value (0.76) are presented. For comparative purposes, results by the IUPAC standard method have also been included (IUPAC, 1992 a). The repeatability or precision of the proposed method was very good and similar to that found for the standard determination (IUPAC, 1992 a). The coefficient of variation ranged from 1.5 to $15 \%$ depending on the content of polar compounds. No significant differences were found between the results obtained by the proposed method and those by the standard method. Therefore, accurate results were provided by the method proposed in this study. 
Table 5

Results for polar compound determination using methyl oleate as internal standard and comparison with the results obtained by the standard method.

\begin{tabular}{|c|c|c|c|c|c|c|c|}
\hline \multirow{2}{*}{ SAMPLE } & \multicolumn{3}{|c|}{$\begin{array}{l}\text { Method proposed (\%) } \\
\quad \text { (variable CF) }\end{array}$} & \multicolumn{3}{|c|}{$\begin{array}{l}\text { Method proposed (\%) } \\
\quad(\mathrm{CF}=0.76)\end{array}$} & \multirow{2}{*}{$\begin{array}{l}\text { Standard } \\
\text { method (\%) }\end{array}$} \\
\hline & Triplicates & Mean & $\begin{array}{l}\text { Standard } \\
\text { deviation }\end{array}$ & Triplicates & Mean & $\begin{array}{l}\text { Standard } \\
\text { deviation }\end{array}$ & \\
\hline HPSO 1 & $\begin{array}{l}6.1 \\
6.2 \\
7.6\end{array}$ & 6.6 & 0.84 & $\begin{array}{l}6.5 \\
6.6 \\
8.1\end{array}$ & 7.1 & 0.90 & 6.7 \\
\hline HPSO 2 & $\begin{array}{l}19.4 \\
19.5 \\
20.6\end{array}$ & 19.8 & 0.67 & $\begin{array}{l}20.8 \\
20.9 \\
22.0\end{array}$ & 21.2 & 0.67 & 20.8 \\
\hline HOSO 1 & $\begin{array}{l}15.6 \\
16.1 \\
14.8 \\
\end{array}$ & 15.5 & 0.66 & $\begin{array}{l}15.6 \\
16.1 \\
14.8 \\
\end{array}$ & 15.5 & 0.66 & 16.3 \\
\hline HOSO 2 & $\begin{array}{c}10.2 \\
9.6 \\
9.7 \\
\end{array}$ & 9.8 & 0.30 & $\begin{array}{c}10.2 \\
9.6 \\
9.7 \\
\end{array}$ & 9.8 & 0.30 & 9.8 \\
\hline HLSO 1 & $\begin{array}{l}24.0 \\
26.4 \\
24.7\end{array}$ & 25.0 & 1.23 & $\begin{array}{l}22.5 \\
24.8 \\
23.2\end{array}$ & 23.5 & 1.18 & 25.7 \\
\hline HLSO 1 & $\begin{array}{l}24.9 \\
24.3 \\
24.9\end{array}$ & 24.7 & 0.35 & $\begin{array}{l}23.4 \\
22.8 \\
23.4\end{array}$ & 23.2 & 0.35 & 25.5 \\
\hline
\end{tabular}

CF, correction factor; For abbreviations see table 1.

Although more accurate results were obtained by applying individual correction factors, an excellent approach was obtained by the application of the mean factor $(0.76)$ found in this study.

\section{FINAL REMARKS}

Either pure FAME or purified FAME from any fat or oil can be used as internal standard in the determination of polar compounds by HPSEC.

The proposed method showed a high precision; however, response factors have to be applied for accurate results. Otherwise, the results obtained for polar compounds would be around $25 \%$ higher than those obtained by the standard gravimetric method.

\section{ACKNOWLEDGEMENTS}

This research work was supported by Junta de Andalucía and Ministerio de Educación y Ciencia (Project AGL 2004-00148). The authors thank Ms Mercedes Giménez for assistance.

\section{REFERENCES}

AENOR 1991. Asociación Española de Normalización. Norma UNE 55-011, Catálogo de Normas UNE, Madrid Dieffenbacher A, Martin E. 1987. Determination of emulsifiers in foods: separation of polar and nonpolar lipids by chromatography on silica-gel microcolumns Rev. Fr. Corps Gras. 34, 323 -328

DGF 2000. German Society for Fat Research, Proceedings of the 3rd International Symposium of Deep-Fat Frying - Final Recommendations. Eur J Lipid Sci Technol. 102, 594.

Dobarganes MC, Velasco J, Dieffenbacher A. 2000. Determination of polar compounds, polymerized and oxidized triacylglycerols, and diacylglycerols in oils and fats. Pure Appl Chem, 72, 1563-1575

Dobarganes MC, Pérez-Camino MC, Gutiérrez González-Quijano R. 1984. Métodos analíticos de aplicación en grasas calentadas. I. Determinación de ésteres metílicos no alterados. Grasas y Aceites 35, 172-177.

Dobarganes MC, Pérez-Camino MC, Márquez-Ruiz G. 1988. High performance size exclusion chromatography of polar compounds in heated and non-heated fats, Fat Sci Technol. 90, 308-311.

Firestone D.1996. Regulation of frying fat and oil, in Perkins EG, Erickson MD.(Eds) Deep frying. Chemistry, nutrition, and practical applications, 323-334.AOCS Press, Champaign, Illinois.

Guinda A, Dobarganes MC, Ruiz-Méndez MV, Mancha M. 2003. Chemical and physical properties of a sunflower oil with high levels of oleic and palmitic acids. Eur J Lipid Sci Technol. 105, 130-137.

IUPAC 1992 a. Standard Method 2.507: Determination of Polar Compounds in Frying Fats, in Standard Methods for the Analysis of Oils, Fats and Derivatives, 7th Edition, International Union of Pure and Applied Chemistry, Blackwell, Oxford, England.

IUPAC 1992 b. Standard Method 2.508: Determination of Polymerized Triglycerides in Oils and Fats by High Performance Liquid Chromatography, in Standard Methods for the Analysis of Oils, Fats and Derivatives, 
7th Edition, International Union of Pure and Applied Chemistry, Blackwell, Oxford, England.

Marmesat S, Rodrigues E, Velasco J, Dobarganes C. 2007. Quality of used frying fats and oils: comparison of rapid tests based on chemical and physical oil properties. Int J Food Sci Technol. 42, 601-608.

Recibido: 27/9/06 Aceptado: 20/2/07 